\title{
Condom use amongst men and women attending a genitourinary medicine clinic
}

\author{
Pauline Handy, RGN, BA, Clinical Nurse Specialist, Department of Genitourinary Medicine, Newcastle General Hospital, \\ Newcastle-upon-Tyne, UK
}

Correspondence: Mrs Pauline Handy, Department of Genitourinary Medicine, Newcastle General Hospital, Westgate Road, Newcastle-upon-Tyne NE4 6BE, UK.Tel: +44 (0) 191219 5011.E-mail:Pauline.Handy@newcastle-pct.nhs.uk

(Accepted 3 May 2004)

Journal of Family Planning and Reproductive Health Care 2004; 30(3): 159-162

\begin{abstract}
Objectives To assess the numbers of patients attending a large genitourinary medicine (GUM) clinic using condoms to reduce the risk of sexually transmitted infections (STIs), and to assess how many patients experienced problems with their use. To elicit whether patients had received any training in the use of condoms.

Design Patient questionnaire.

Participants 300 male and 300 female adult attenders at a GUM clinic.

Methods Participants were randomly selected from those attending and asked to complete an anonymous questionnaire, which was placed in a sealed box in the consulting room.

Results Condom use is erratic, with most responders indicating that they only sometimes use condoms. More female than male patients report condom accidents. Male participants were less likely to recall being given any training in condom use at school than women. Women attending family planning clinics for condoms were unlikely to be offered training in their use.

Conclusions The majority of participants continue to place themselves at risk of STIs through inconsistent use of condoms or condom accidents. More emphasis should be placed on formal education in the use of condoms both at school and health clinics where patients are likely to obtain supplies of condoms.
\end{abstract}

\section{Key message points}

- Condom use remains erratic, despite awareness of the risks.

- Training in condom use is lacking for both men and women.

- Training should be offered whenever condoms are supplied by clinics.

\section{Introduction}

A sustained rise in sexually transmitted infections (STIs) seen both in the author's department and nationally suggests that the use of condoms as a method of STI prevention is decreasing. The National Strategy for Sexual Health and $H I V^{1}$ has focused the attention of health care professionals on these sustained increases in STIs and the impact upon society.

We carried out an anonymous, self-administered, questionnaire survey of attenders at a genitourinary medicine (GUM) clinic to assess the difficulties with, and level of formal training in, the use of condoms.

The results of this survey suggest that although the majority of respondents are aware of the need to use condoms to protect against STIs, their use remains erratic with many men and women also indicating problems with their use.

\section{Methods}

On their first visit to the clinic 600 consecutive participants (300 men and 300 women) were invited to complete an anonymous, self-administered questionnaire relating to their use of condoms. The questions included in the questionnaire are listed in Box 1. Female patients were also asked questions about their methods of contraception. Each questionnaire was then placed in a sealed box in the clinical examination room.

Data were stratified by sex and, for men, sexuality. Associations between gender and condom use were explored using the Chi-square test. The male group was subdivided into 251 heterosexual men and 49 homosexual/bisexual men.

\section{Results}

The mean age of the heterosexual men was 29.8 years, homosexual men 27.3 years and bisexual men 33 years. No male responders were aged under 16 years. The mean number of partners identified during the previous 12 months for heterosexual men was 2.8 , homosexual men 6.4 and bisexual men 4.5 .

The mean age of the women was 24.1 years, with a mean number of partners in the previous 12 months of 2.7 . A total of 13/300 (4\%) of the female respondents were aged under 16 years.

Summaries of the responses given to the questions appear below.

\section{Q1. Do you use condoms?}

Of the 251 heterosexual men, 217/251 (86\%) answered yes and $27 / 251(11 \%)$ no. There was no answer from $7 / 251$ (3\%) men. A total of 237/300 (79\%) women stated yes and $63 / 300(21 \%)$ no. All 49 homosexual/bisexual respondents answered yes.

Responses were then analysed by age groups as shown in Table 1. The results show that more than $90 \%$ of heterosexual men aged under 30 years used condoms $(159 / 169)$. More than $80 \%$ of women aged under 30 years also stated that they used condoms (201/251).

Q2. Do you use condoms always, sometimes or never? A total of 41/217 (19\%) of heterosexual men answered that they always used condoms, with 176/217 (81\%) stating

Box 1: Questions included in the self-administered questionnaire
Q1 Do you use condoms?
Q2 How often do you use them?
Q3 Do you have problems with them?
Q4 What is the main problem?
Q5 Who taught you how to use a condom?
Q6 Where do you get your condoms from?
Q7 Do you check the kite mark and expiry date before you use them?
Q8 Are your sexual partners female, male or both?
Q9 How old are you?
Q10 How many partners have you had in the past 12 months?


Table 1 Responses concerning respondents' usage of condoms ever

\begin{tabular}{|c|c|c|c|c|c|c|}
\hline \multirow[t]{2}{*}{ Respondents } & \multicolumn{5}{|c|}{ Respondents' age (years) } & \multirow{2}{*}{$\begin{array}{l}\text { No } \\
\text { answer }\end{array}$} \\
\hline & $<20$ & $21-30$ & $31-40$ & $41-50$ & $51+$ & \\
\hline \multicolumn{7}{|l|}{ Heterosexual men } \\
\hline Yes $(n=217)$ & 43 & 116 & 41 & 14 & 3 & 0 \\
\hline No $(n=27)$ & 2 & 8 & 8 & 4 & 5 & \\
\hline No answer $(\mathrm{n}=7)$ & & & & & & 7 \\
\hline \multicolumn{7}{|l|}{ Homosexual men } \\
\hline Yes $(n=41)$ & 4 & 15 & 15 & 6 & 1 & \\
\hline \multicolumn{7}{|l|}{ Bisexual men } \\
\hline Yes $(n=8)$ & 2 & 2 & 1 & 3 & 0 & \\
\hline \multicolumn{7}{|l|}{ Women } \\
\hline Yes $(n=237)$ & 85 & 116 & 27 & 9 & 0 & \\
\hline No $(n=63)$ & 25 & 25 & 10 & 3 & 0 & \\
\hline
\end{tabular}

sometimes. Of the homosexual/bisexual men, 27/49 (55\%) always used condoms, with 21/49 (43\%) stating they used them sometimes and 1/49 failing to answer. Of the women surveyed, 68/237 (29\%) always used them and 154/237 $(65 \%)$ sometimes used them. The question was not answered by $15 / 300(5 \%)$ women. In total only $68 / 300(23 \%)$ men and $68 / 300(23 \%)$ women stated that they always used condoms.

Q3. Do you have problems with condoms always, sometimes or never?

Analysis of this question demonstrated that in heterosexual men 14/217 (7\%) always had problems with condoms, $101 / 217$ (47\%) sometimes had problems and 102/217 (47\%) never had problems. Of the homosexual/bisexual men, 2/49 (4\%) always had problems, 21/49 (43\%) sometimes had problems and 23/49 (47\%) never had problems. A total of $3 / 49(6 \%)$ men failed to answer the question. In women 13/237 (6\%) stated that they always had problems, 136/237 (57\%) sometimes had problems and 88/237 (37\%) never had problems. Therefore, more women than men perceived difficulties with condom use (Chisquare $5.1, \mathrm{p}<0.05)$

Q4. What is your main problem with condoms?

The problems identified by all respondents are summarised in Table 2. Of the total 503/600 (84\%) men and women who stated that they use condoms, 287/503 (57\%) admitted to always or sometimes having problems with condom use, with $233 / 287(81 \%)$ indicating that the problem experienced was that of the condom either coming off or tearing during use.

Q5. Who taught you how to use condoms?

Of all the 300 men completing the questionnaire, 108/300 $(36 \%)$ answered that they had received formal training at school and $7 / 300(2 \%)$ from other health care professionals. A total of 134/300 (45\%) men indicated that they never been given any formal training in the use of

Table 2 Problems with condom use identified by the respondents

\begin{tabular}{rrl}
\hline Men (n) & Women (n) & Problem \\
\hline 157 & 141 & No answer \\
52 & 64 & Condom tears \\
44 & 73 & Condom comes off \\
24 & 8 & Condom too small \\
8 & 5 & Don't like them (no reason given) \\
5 & 6 & Cause irritation \\
4 & 3 & Have problems putting them on \\
2 & - & Lose their erection when putting them on \\
2 & - & Condom too big \\
1 & - & Puts them on inside out \\
1 & - & Has lubrication problems
\end{tabular}

Table 3 Responses concerning whether the respondents were taught how to use condoms

\begin{tabular}{|c|c|c|c|c|c|c|}
\hline \multirow[t]{2}{*}{ Respondents } & \multicolumn{5}{|c|}{ Respondents' age (years) } & \multirow{2}{*}{$\begin{array}{l}\text { No } \\
\text { answer }\end{array}$} \\
\hline & $<20$ & $21-30$ & $31-40$ & $41-50$ & $51+$ & \\
\hline \multicolumn{7}{|l|}{ Heterosexual men } \\
\hline Yes $(n=114)$ & 33 & 65 & 11 & 5 & 0 & \\
\hline No $(n=127)$ & 15 & 62 & 34 & 9 & 7 & \\
\hline No answer $(n=10)$ & & & & & & 10 \\
\hline \multicolumn{7}{|c|}{ Homosexual/bisexual men } \\
\hline Yes $(n=17)$ & 6 & 5 & 3 & 2 & 1 & \\
\hline No $(\mathrm{n}=30)$ & 0 & 12 & 11 & 7 & 0 & \\
\hline No answer $(\mathrm{n}=2)$ & & & & & & 2 \\
\hline \multicolumn{7}{|l|}{ Women } \\
\hline Yes $(n=146)$ & 73 & 63 & 9 & 1 & & \\
\hline No $(n=146)$ & 39 & 66 & 30 & 11 & 0 & \\
\hline No answer $(n=8)$ & & & & & & 8 \\
\hline
\end{tabular}

condoms. The question was not answered by 51/300 (17\%) men.

A total of $141 / 300(47 \%)$ women indicated that they had received training in the use of condoms at school. A further $74 / 300(25 \%)$ women stated that they had not received any formal training. Health care professionals had taught 9/300 (3\%) women. Some 76/300 (25\%) women failed to answer the question. A large number of male and female respondents $(127 / 457 ; 28 \%)$ failed to answer this question, therefore possibly leading to bias in the interpretation of the results. However, the figures that were obtained show that significantly more women than men recall being taught at school how to use condoms. (Chisquare 20.7, p<0.0001) (Tables 3 and 4).

Q6. Where do you get your condoms?

Heterosexual men responded that 166/217 (76\%) bought their condoms, 35/217 (16\%) obtained them from contraception and sexual health services and 8/217 (4\%) obtained them from Streetwise (a local young people's drop-in centre). The question was not answered by $8 / 217$ (4\%) men.

Of the homosexual/bisexual respondents, 15/49 (31\%) indicated that they obtained their condoms from gay organisations such as Mesmac, with 12/49 (25\%) obtaining them from bars. A total of 15/49 (31\%) answered that they bought them elsewhere, with $4 / 49(8 \%)$ being provided with condoms by Streetwise and a further 2/49 (4\%) from

Table 4 Responses concerning who taught respondents to put on a condom

\begin{tabular}{|c|c|c|c|c|c|c|}
\hline \multirow[t]{2}{*}{ Respondents } & \multicolumn{5}{|c|}{ Respondents' age (years) } & \multirow{2}{*}{$\begin{array}{l}\text { No } \\
\text { answer }\end{array}$} \\
\hline & $<20$ & $21-30$ & $31-40$ & $41-50$ & $51+$ & \\
\hline \multicolumn{7}{|l|}{ Heterosexual men } \\
\hline Self $(n=105)$ & 10 & 48 & 30 & 11 & 6 & \\
\hline School (n = 97) & 34 & 56 & 5 & 2 & 0 & \\
\hline $\begin{array}{l}\text { Health care } \\
\text { professional }(n=6)\end{array}$ & 1 & 3 & 1 & 1 & 0 & \\
\hline No answer $(n=43)$ & & & & & & 43 \\
\hline \multicolumn{7}{|c|}{ Homosexual/bisexual men } \\
\hline Self $(n=29)$ & 0 & 11 & 12 & 5 & 1 & \\
\hline School $(\mathrm{n}=11)$ & 4 & 5 & 1 & 1 & 0 & \\
\hline $\begin{array}{l}\text { Health care } \\
\text { professional }(n=1)\end{array}$ & 0 & 0 & 0 & 1 & 0 & \\
\hline No answer $(\mathrm{n}=8)$ & & & & & & 8 \\
\hline \multicolumn{7}{|l|}{ Women } \\
\hline Self $(n=74)$ & 18 & 33 & 15 & 8 & 0 & \\
\hline School $(n=141)$ & 65 & 65 & 10 & 1 & 0 & \\
\hline $\begin{array}{l}\text { Health care } \\
\text { professional }(n=9)\end{array}$ & 4 & 3 & 2 & 0 & 0 & \\
\hline No answer $(n=76)$ & & & & & & 76 \\
\hline
\end{tabular}


contraception and sexual health services. The question was not answered by $1 / 49(2 \%)$ men.

Women indicated that $132 / 237(56 \%)$ bought their condoms, 72/237 (30\%) obtained them from Contraception and Sexual Health Services, 7/237 (3\%) were supplied by their partners, 15/237 (6\%) obtained them from Streetwise and $8 / 237(3 \%)$ from their general practitioner (GP). A total of $3 / 237(1 \%)$ women failed to answer the question.

\section{Q7. Do you ever check the expiry date and kite mark on condoms?}

Of the heterosexual men questioned, 70/217 (32\%) stated that they always checked the expiry date and kite mark with 59/217 (27\%) stating sometimes and 88/217 (42\%) never.

A total of 17/49 (14\%) homosexual/bisexual men stated that they always checked, 19/49 (39\%) sometimes checked and 11/49 (22\%) never checked. The question was not answered by $2 / 49$ (4\%) men.

Of the women questioned, 119/237 (50\%) said they always checked, 55/237 (23\%) sometimes checked and $63 / 237(27 \%)$ never checked. The results show that significantly more women than heterosexual or homosexual men check the expiry date on condoms (Chisquare 16.1 and $6.2, p<0.001$ and $p<0.05$, respectively).

\section{Type of contraception}

Of those women completing the questionnaire, 57/300 $(19 \%)$ stated that condoms were their only form of contraception. A further 148/300 (49\%) women took the oral contraceptive pill, 15/300 (5\%) used Depo Provera injections, 13/300 (4\%) an intrauterine device and 9/300 had a contraceptive implant. A total of 7/300 (2\%) women indicated that either they or their partner had been sterilised, with $1 / 300(0.3 \%)$ female respondents trying for pregnancy. A large proportion of the women $(50 / 300 ; 17 \%)$ failed to answer the question.

Of the 72/237 (30\%) women who obtained their condoms from family planning clinics (FPCs), 36/72 $(50 \%)$ indicated that they had not received any formal training in how to use them. Of the remaining 36/72 (50\%) women who stated that they had received training, 35/36 (97\%) had been taught at school and 1/37 (3\%) by an unspecified health care professional. This suggests that of the group surveyed, none had been provided with training by family planning staff

GPs were responsible for providing 8/237 (3\%) women with condoms, with $4 / 8(50 \%)$ being taught at school and 4/8 (50\%) not having received any training. Streetwise provided $15 / 237(6 \%)$ of the women with condoms, with 5/15 (33\%) indicating that they had never received any training in the use of condoms.

\section{Discussion}

In England alone, the number of visits to GUM departments has doubled over the last decade ${ }^{2}$ and now stands at over one million per year. Infection with chlamydia has now become the most common STI, with an increase of $15 \%$ in males and $13 \%$ in females between 2001 and $2002 .^{3}$ A recent, multicentre trial on the spread of chlamydia 4 found a higher than expected prevalence $(8.3 \%)$ in patients attending their GP, thus highlighting the need for increased awareness of STIs within the community setting. Overall, gonorrhoea has also shown an increase of 9\% between 2001 and 2002. Diagnoses of primary and secondary syphilis in England, Wales and Northern Ireland showed the largest relative increase during the period 1998-2002, with diagnoses rising by $803 \%$ largely as a result of localised outbreaks that occurred during the period. ${ }^{3}$ HIV prevalence by the end of
2003 is expected to be $40 \%$ higher than the 1999 level. ${ }^{5}$ Behavioural surveillance studies have confirmed declining rates of condom use among HIV-positive men, and in particular those with sero-discordant partners or partners of unknown status. ${ }^{6}$ These figures would suggest that the safer sex message is not having any impact on the reduction of STIs in the UK.

Research into the use of condoms and lifestyle reveals that more than four in ten Britons $(43 \%)$ are taking no measures to protect themselves from HIV/AIDS and other STIs. ${ }^{7}$ Recent information from the 2002 GRASP Study 8 indicates that $24 \%$ of gonococcal infection identified in 2002 was amongst homosexual and bisexual men. Around $28 \%$ of all those diagnosed with gonorrhoea have been previously infected with gonorrhoea, and $34 \%$ of infected individuals were also diagnosed with a concurrent STI. A low level of symptomatic infection amongst female GUM clinic attenders was noted with only $63 \%$ of those diagnosed with gonorrhoea reporting symptoms compared to $91 \%$ of males.

The figures would suggest that although the majority of respondents are aware of the need to use condoms to protect against STIs, their use remains erratic with many respondents indicating problems with their use.

It is clear from this study that fewer than $25 \%$ of heterosexual men and women surveyed always used condoms, with only $55 \%$ of homosexual/bisexual men admitting to using them all of the time. In fact $70 \%$ of the men and women participating in this survey admitted that they only sometimes used condoms. Although allowances must be made for those men and women in long-term monogamous relationships where condom use is negligible, the figures would still suggest that the majority of the respondents are still at risk of STIs.

Significantly more women than men answered that they had been taught how to use condoms whilst at school, possibly demonstrating a bias towards sexual health education aimed at girls/women. Therefore, a greater emphasis needs to be placed on formal sex education for boys/men either at school or by health care professionals. The study also demonstrated that significantly more women than men checked the expiry date and kite mark on condoms before using them.

It could be argued that the problems identified with condom use are due to lack of training or training being too little and too long ago. Training at school may not have been seen as relevant and forgotten about. The question of whether such training should be repeated at school on several occasions to reinforce the message should be considered. However, although not presented here, the data collected showed no correlation between the lack of training in the use of condoms and condom accidents. In view of the responses from those participating in this survey, it could also be postulated that the opportunity should be taken to instruct men and women in the correct use of condoms when attending either GUM clinics, FPCs or GPs.

The results of this study tend to suggest that FPCs are making the assumption that women attending for condoms have received training in their use elsewhere. To a lesser extent it would appear to also be true of GPs and young people's services. Although training may be provided to attenders, it is possible that it is restricted to those younger patients seen, or it may be simply that the question is not being asked. Some health care professionals may perceive it as an inappropriate question to ask older attenders. However, this study suggests that the opportunity should be taken at this time to provide safer sex advice such as partner reduction and consistent condom use.

It is acknowledged that this study would have been enhanced by the inclusion of a direct question to 
responders to elicit whether they had been offered any instruction in the use of condoms when supplied by GUM clinics, GPs or FPCs. In the current climate of escalating STIs it is essential that a comprehensive and effective strategy is employed by all health care professionals to ensure that patients are aware of the need for condoms and are competent in their use. Such training would help minimise the risk of slippage or breakage, perhaps encouraging those who have previously had difficulties with using condoms to try again.

Statements on funding and competing interests

Funding. None identified.

Competing interests. None identified.

References

1 Department of Health. National Strategy for Sexual Health and HIV. London, UK: Department of Health, 2001.

2 PHLS (England Wales \& Northern Ireland), DHSS \& PS (Northern Ireland) and the Scottish ISD (D) 5 Collaborative Group (ISD SCIEH and MSSVD). Trends in Sexually Transmitted Infections in the UK 1990-1999. New Episodes Seen at Genitourinary Medicine Clinics. London, UK: Department of Health, December 2000. ISBN 090011 44495.

3 Health Protection Agency (HPA). Epidemiological Data: Chlamydia. London, UK: HPA, 2003. http://www.hpa.org.uk/infections.

4 Underhill G, Hewitt G, McLean L, et al. Who has chlamydia? The prevalence of genital tract Chlamydia trachomatis within Portsmouth and South East Hampshire, UK J Fam Plann Reprod Health Care 2003; 29(1): 17-20

5 Centers for Disease Control and Prevention (CDC). AIDS and HIV Infection in the UK: Monthly Report, vol. 10(50); 453-454. Atlanta, GA: CDC, 2000.

6 Fenton KA. Sexual health and HIV positive individuals: emerging lessons from the recent outbreaks of infectious syphilis in England. Commun Dis Public Health 2002; 5: 4-6.

7 Durex report. Survey into sexual attitudes and behaviour in Britain. SSL International plc, 2002. http://army.mod.uk/linked files/bfghs/ DUREX pdf.

8 GRASP: The Gonococcal Resistance to Antimicrobials Surveillance Programme Annual Report (2002). Available from: Communicable Disease Surveillance Centre, Public Health Laboratory Service, 61 Colindale Avenue, London NW9 5EQ, UK.

\section{The 4-0-8 Sheffield Fund}

In 2001 the 4-0-8 Young People's Consultation Centre Ltd, Sheffield, UK made a significant donation to the Faculty of Family Planning and Reproductive Health Care (FFPRHC) for the purpose of funding training for health care professionals who had limited funding for attending training meetings. Any person working in the field of reproductive and sexual health care within the UK may apply. Approximately $£ 1000$ will be allocated every 3 months, either as a single award or divided between the successful applicants.

For details on how to apply to the 4-0-8 Sheffield Fund visit the Faculty website at www.ffprhc.org.uk. For an application form apply to: Chair of the Education Committee, Faculty of Family Planning and Reproductive Health Care of the RCOG, 27 Sussex Place, Regent's Park, London NW1 4RG, UK. Closing date: 6 months prior to the event for which funding is applied for.

\section{But is she positive?}

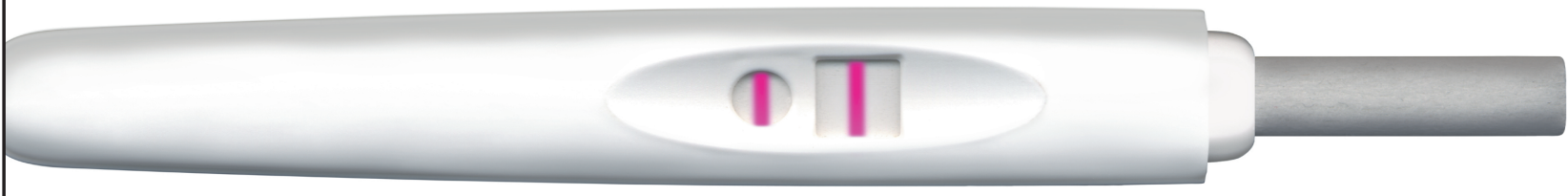

Your next patient is pregnant but doesn't want to be.

Where next? As a registered charity since 1968, bpas has offered affordable abortion care for women. We provide almost 50,000 abortions a year (including service agreements) and can offer all the professional help your patient needs.

bpas has a nationwide network of clinics and consultation centres. There are no long waits for appointments. We can offer a choice of times, clinics and procedures. All it takes to arrange an appointment is one call to the bpas Actionline on 08457304030.

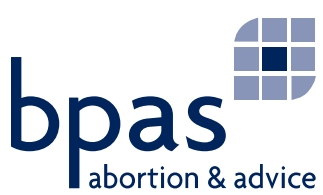

ACTIONLINE 08457304030 